\title{
The Cognitive Science of PowerPoint
}

\author{
Jeffrey W. Paul, Jillian Seniuk Cicek, \\ Price Faculty of Engineering, University of Manitoba \\ umpau159@myumanitoba.ca, Jillian.SeniukCicek@umanitoba.ca
}

\begin{abstract}
PowerPoint, Google Slides, Keynote, Prezi and other visual tools have become ubiquitous in modern classrooms, business meetings, and engineering briefings. Unfortunately, many slides are poorly designed with a high cognitive load. That is, they either contain too much information or have poorly organized information. Given the inverse correlation between cognitive overload and memory, reducing the cognitive load of slides can lead to more effective presentations - improving communication, retention, and instruction.

The paper will first provide an overview of cognitive load theory and its significance/relation to human factors engineering. Then, selected theories from cognitive psychology, including the expert-novice divide, dualchannel theory, gestalt principles, and constructivism will be introduced. Using authentic examples of classroom slides, this paper will demonstrate how these cognitive theories' practical application can reduce cognitive load. This paper aims to be a "why-to" as well as a "how-to" guide for improving visual pedagogical aids, specifically, slides, in the engineering classroom.
\end{abstract}

Keywords: Visual Rhetoric, Slide Design, Classroom Learning Environment, Pedagogical Content Knowledge, Instructional Design

\section{INTRODUCTION}

The ability to communicate highly technical information is a key skill for engineers. Typically, technical presentations have both verbal and visual elements, with presenters relying heavily on slides to communicate with their audience. However, Edward Tuft, in his essay "PowerPoint does Rocket Science" [1], discusses the fact that presentation tools often impede rather than enable communication. Visual aids are overrun with technical information, causing the message to be lost. One slide at the center of his analysis is shown at Figure 1.

As Tufte argues, though all the information on the slide is technically correct, it does not inform the audience, it does not communicate a message, and, in fact, it obscures the critical information: i.e., that the test data used to validate the Crater program - which simulates the effect of debris impact - had a maximum size of 3 cubic inches. Given that the actual piece that struck the Columbia was estimated at 1920 cubic inches, this means that the simulation program was far outside its validated range.

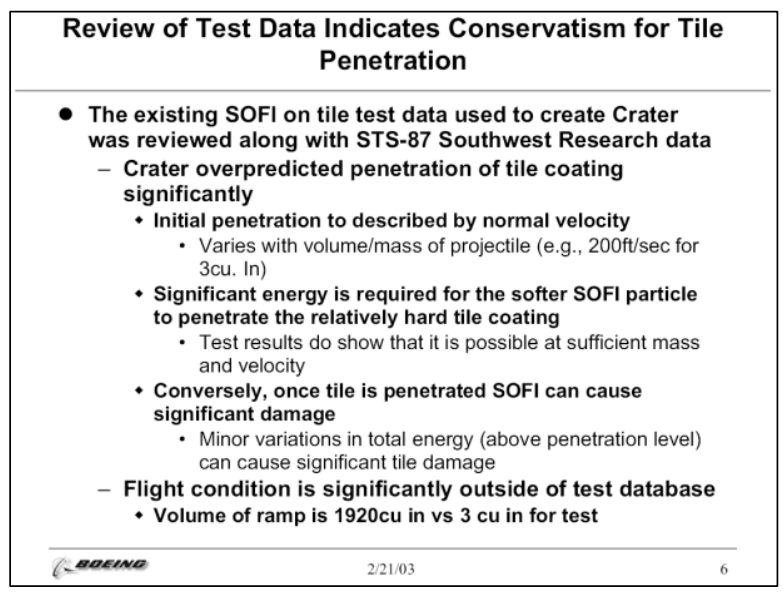

Figure 1 - NASA Columbia Briefing Slide [2]

The issue of ineffective communication perpetrated by poor slide design extends to the engineering classroom, where, though there are many initiatives that focus on active learning (e.g., problem-based learning [3], design engineering [4], student-centric methods [5], etc.), the lecture remains the most common pedagogical tool [6], [7]. Given the preponderance of lectures, it perhaps is not surprising that engineering instructors rank near the bottom of university instructors with respect to student engagement and effective learning strategies [8]. While several factors may lead to these low rankings, such as the passive learning aspect of the lecture delivered via PowerPoint slides (or similar software presentation tools), this paper argues, unlike Tufte, that it is not the tool that is the issue, but the manner in which it is used.

Visual rhetoric and slide design specifically is an active field (both in academia and industry); the characteristics of effective slide design have been discussed by engineering/technical communicators and instructors in this discipline. However, despite the fact that there are excellent manuals [9], [10], articles [11], [12] conferences [13], [14], websites [15], [16] and organizations [17], [18] on how to improve presentations and slide design, few of these resources explain why to make the suggested changes. Given that research has 
revealed if learners know why as well as what, they are more likely to apply the learned techniques appropriately and consistently [19], the aim of this paper is to provide a theoretical background to reinforce the practical suggestions of effective slide design

Specifically, we will show how an understanding of Cognitive Load Theory explains many of the suggestions made by others to improve slide design. Effective visual design (or visual rhetoric) can reduce cognitive overload and thus improve communication, retention and learning. After an introduction on Cognitive Load Theory fundamentals, each subsequent section will first provide a brief overview of a theory from cognitive psychology or human factors engineering, and second, apply the theory to authentic examples of slides from engineering classes. The goal is to explain and demonstrate.

Though this paper is directed at engineering instructors, the takeaways are equally applicable to students and professionals.

\section{COGNITIVE LOAD THEORY}

The fundamental foundation for our argument is based on Cognitive Load Theory, which, in brief, states that human information processing capability is based on limited working memory paired with unlimited long-term memory [20]. Essentially, working memory (also known as short-term memory) has a short half-life and low capacity. If overwhelmed, a bottleneck is formed in the transfer of knowledge into long-term memory. This has been experimentally validated [21] under various conditions, and is shown graphically in Figure 2.

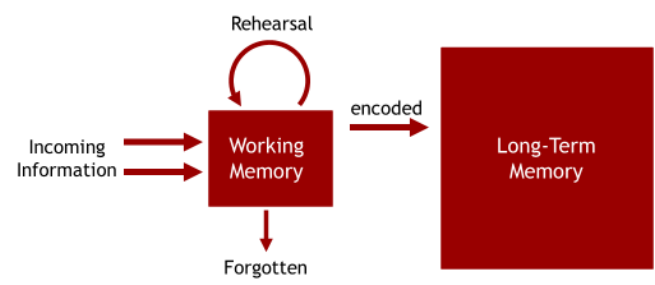

Figure 2 - Working Memory Bottleneck

The central aspect of this theory of working memory is its limited information capacity. If too much information arrives, it will be forgotten before it can be encoded in long-term memory for future recall. As well, information is only retained in working memory for a short period of time - thus requiring rehearsal (e.g., repeating a phone number to yourself) in order to retain the information for a longer period of time.

Cognitive Load Theory has been linked to learning by other authors. For example, Mayer's seminal work on multimedia learning [22] is based on the application of this theory. In addition, the theory has been refined to include specific types of cognitive load (intrinsic, extrinsic, and germane), as well as the role of other factors such as sensory systems, attention, and decision schemas. The interplay of these other factors with working and long-term memory is shown in Figure 3. This model was developed from mental workload studies in human factors engineering.

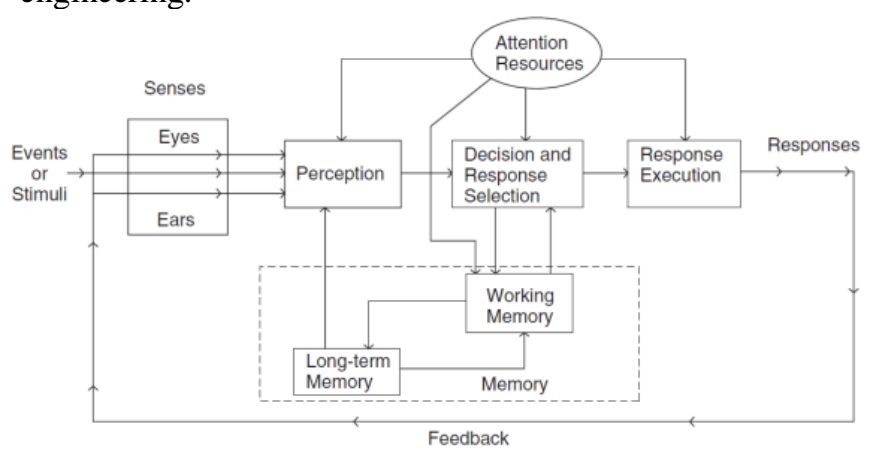

Figure 3 Model of Human Information Processing [23]

For the purposes of our analysis, the simplistic cognitive model of memory shown in Figure 2 and at the lower section of Figure 3 will suffice. Specifically, we are focusing on a limited working memory interacting with an unlimited long-term memory. By applying relevant theories, we can show how to reduce the cognitive load created by poor slide design.

Note that there is no doubt that many of the concepts instructed in engineering classrooms are complex. They require a high cognitive load by the student in order to learn these concepts. However, there is no need to add unintended complexity through slide design. In fact, studies have shown that desirable difficulty [24] is essential for effective learning - thus, the goal is not to eliminate the necessary cognitive load but to eliminate unnecessary cognitive load.

A final caveat: there are many theories and models on how the brain works and learning occurs, and our understanding of the brain continues to evolve. This paper is not a comprehensive overview of these theories. As well, we should accept the truism that all models are wrong, but some models are useful. The theories and models discussed in this paper should not be treated as definitively prescriptive but rather suggestively informative. The concepts can be used to help the instructor understand how information processing works as related to slides in order to achieve improved learning outcomes. The key aspect for this analysis is that if working memory becomes overloaded, learning is impaired as information is dropped or forgotten.

\section{REDUCING COGNITIVE LOAD}

In each of the following sections, we will first introduce a theory that addresses a specific aspect of 
cognitive load. Then we will demonstrate how cognitive load can be reduced by applying the theory to an example slide. Central to each of these sections is helping the instructor develop a more comprehensive understanding of working memory. Though lay knowledge of working memory is often simplistically quoted in popular media as Miller's Law (i.e., working memory is limited to $7 \pm 2$ things) [25], there are nuances and new understandings of working memory and its capacity that can be exploited to improve learning.

Note, all the example slides in this paper are slides from the first author's instruction, though anonymized or adapted with copyright-free imagery.

\subsection{Expert-Novice Divide}

One of the hidden difficulties instructors have in developing course material is their own intrinsic competency. This is often called the expert-novice divide [26] and is related to the expert's ability to recall large amounts of related information in a single chunk. Essentially, both the expert and the novice are still limited by the Miller's Law-like capacity of working memory; however, the amount of content of each recalled item is significantly different between the expert and novice.

This was demonstrated experimentally by Chase and Simon [27] with chess. In this experiment, expert chess players were able to recall the positions of chess pieces on a chessboard with much greater accuracy than non-chess players. Chase and Simon found that rather than recalling the position of each piece, the experts memorized the position of all the pieces as a single chunk of information representing a specific game state. Novices, on the other hand, memorized the individual position of each piece as independent chunks. As a simplistic example, think of the starting positions of all 32 pieces on a chessboard. If you have some familiarity with the rules of chess, you can probably recreate the starting position with little difficulty. You have recalled 32 pieces of information in one chunk. An expert can recall more than just the starting position as a game state. Novices are much more limited and, other than the initial set-up, must resort to memorizing the position of each piece as an independent chunk.

Chase and Simon also found that the expert's advantage was lost when the pieces were distributed randomly in illegal positions rather than as they might occur naturally in a game. In these cases, the expert had to recall each piece independently, similar to novices, and demonstrated similar memory to the novices.

For our purposes, the key aspect of this theory is that a slide will often have a low cognitive overhead for the instructor. They are an expert in the topic. They have the expert's ability to chunk the information on the slide into a single piece of information. Thus, the slide is cognitively simple for the instructor; however, to the student, the slide may have numerous chunks of information, and it may be cognitively overwhelming.
As an example, see the slide shown in Figure 4. This slide, containing the same model introduced to you in Figure 3, was utilized in a human factors engineering course to help the students build an internal model (or schema) of human information processing. This exact image was introduced at the start of almost every lecture throughout the course, supported with animation to highlight which phase of the model would be developed in the lecture.

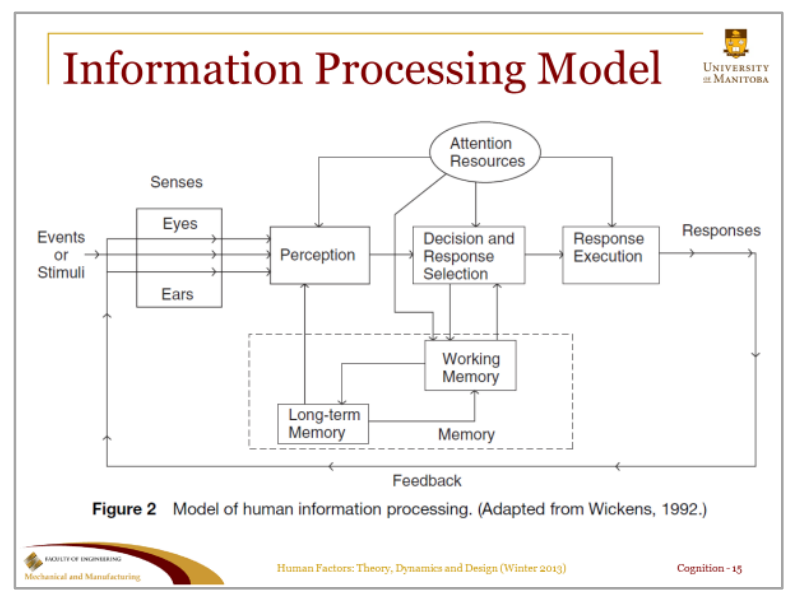

Figure 4 Model of Human Information Processing

However, on the last day of the course (prior to the exam), when asked to draw this model, fewer than $20 \%$ of the students could recreate the model.

For the instructor, the slide was a single chunk of information, a single elegant model that accurately represented the interplay of the various aspects of human information processing. To the student, however, this was a confusing graphic containing numerous chunks of information.

To solve this issue, the model was replaced by a series of graphics similar to that shown in Figure 5. The model, rather than being completely introduced at the outset as shown in Figure 4, was built iteratively in small pieces over

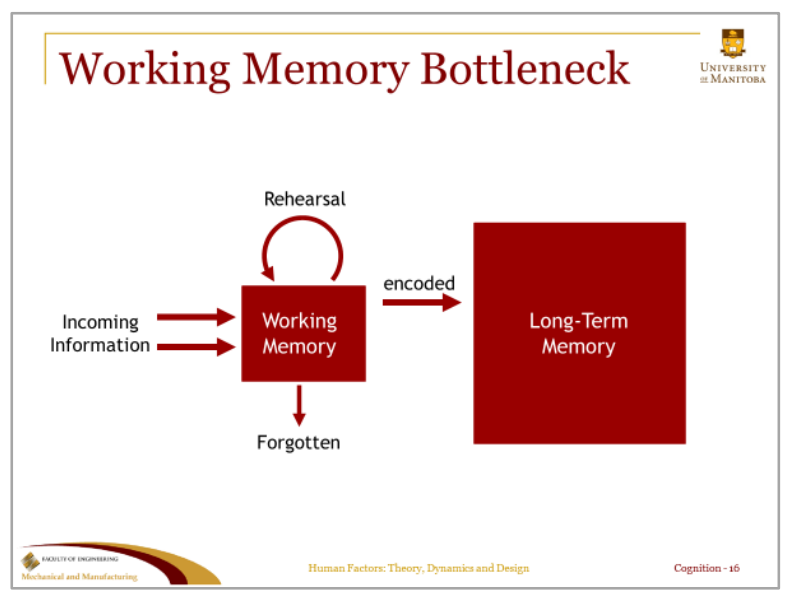

Figure 5 Simplified Information Processing Model 
multiple classes, enabling the students time to develop their own internal model.

This second slide reduces the cognitive load on the novice as it includes less unfamiliar or new information. Though this may seem overly simplistic to the instructor, it is appropriate for the novice student.

The key takeaway is that instructors should make slides as simple as possible by reducing each slide to one idea, as seen from the novice's perspective. Use animation or multiple slides to build to more complex ideas. This will reduce the cognitive load on the students and ensure improved retention.

\subsection{Dual-Channel Theory}

Another nuance to the functioning of working memory is that it is not a singular mechanism, but it has two distinct mechanisms - a verbal and a visual channel (specifically the phonological loop and the visuospatial sketchpad) [28]. Miller's capacity limits apply independently to both mechanisms. Specifically, you can hold 1-2 seconds of speech in your verbal working memory, as well as 1-4 images in your visual working memory [29]. A task can put demands on either or both of these channels. Cognitive overload can occur when only one channel is overloaded. Reinforcement occurs when related information is presented to both channels. This has two implications for slide design.

First, in general, you should ensure that images and text are directly related to reinforcing the message. Using clip art or tangentially related stock images, as shown in Figure 6, can distract rather than reinforce.

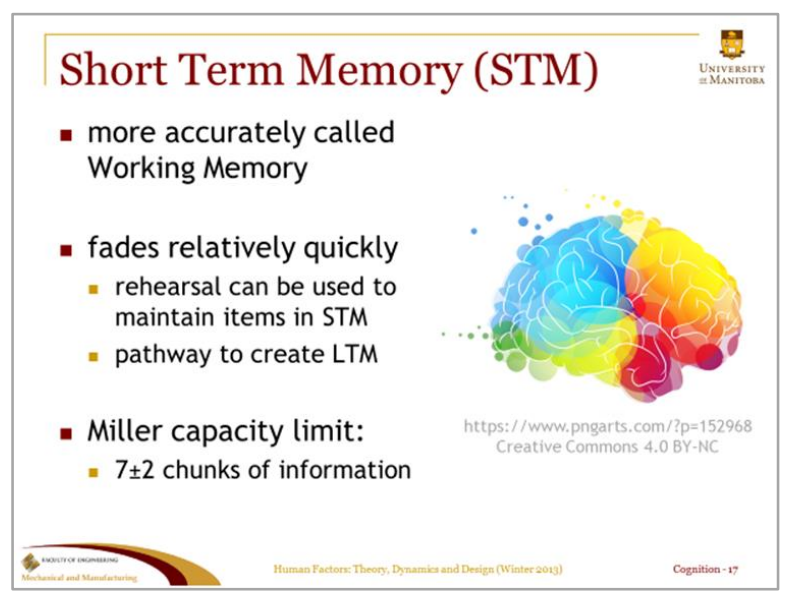

Figure 6 Slide with text and irrelevant image

In this example, the clipart image of the brain adds little to focus the content or model. There are many examples of distracting images (such as using a picture of the Golden Gate Bridge to represent a network bridge in a computer science class), and though these images can attract the attention of the student (and thus appear to create engagement), unrelated imagery can load the working memory with irrelevant information. A revised example is shown in Figure 7 where the imagery reinforces the text.

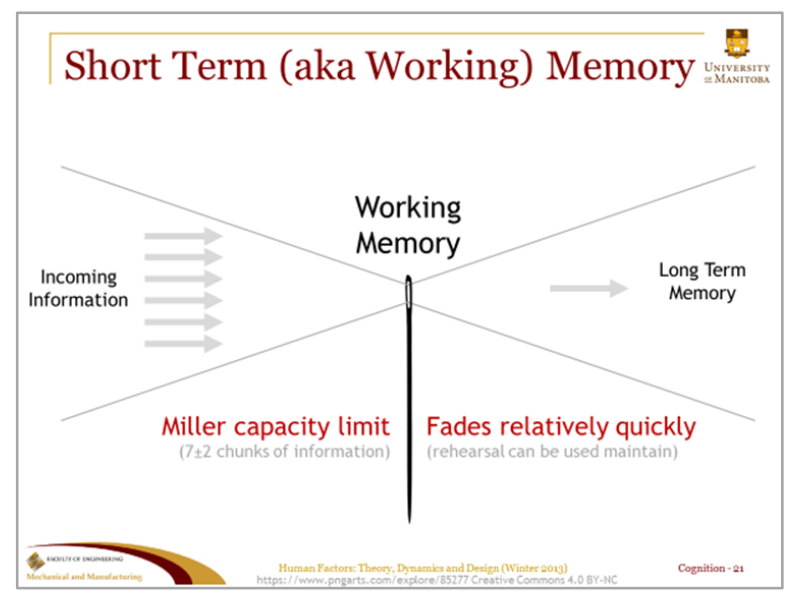

Figure 7 Using Relevant Imagery

Note that in Figure 7, though one could argue that a needle is unrelated to the concept of working memory, this image is being used to capture a known characteristic of a needle, i.e., the limited size of the eye of the needle. Thus, the imagery is reinforcing the verbal message of limited capacity.

In addition, Figure 6 also highlights the second key implication of dual-channel theory for the instructor. You should avoid text-heavy slides where the instructor reads the bullet points out loud. The issue here is that the speaking voice and the written text both use the same channel (the phonological loop), and when both are active, this tends to overload the channel. This forces the students to ignore either your voice, the text on the slide, or both. Another example of this is shown in Figure 8. This Systems Engineering Definition was considered an essential definition for the course; however, displaying the definition while reading it out loud serves no useful purpose and, in fact, needlessly increases students' verbal cognitive load. This almost ensures that students will be unable to effectively process and retain this information. This becomes an ineffective pedagogical strategy, one that is too often employed.

An improved slide applying the principles of dualchannel theory is shown in Figure 9. In this example, the definition is still displayed; however, rather than reading, the instructor uses animation and highlighting to focus the student's visual attention on the three key elements of the definition. This animation is repeated with a second definition and similar highlighting. Key in this example is that neither definition is read to the students. This would cause a cognitive overload of the phonological loop mechanism in their working memory. Rather, the definition is displayed, the students are given time to read, then the instructor uses animation (i.e., the visual channel) to attract attention to the key components of the definition. 


\section{Systems Engineering Definition}

- An interdisciplinary approach that encompasses the entire technical effort and evolves into and verifies an integrated and life cycle balanced set of system people, products, and process solutions that satisfy customer needs (EIA Standard IS-632)

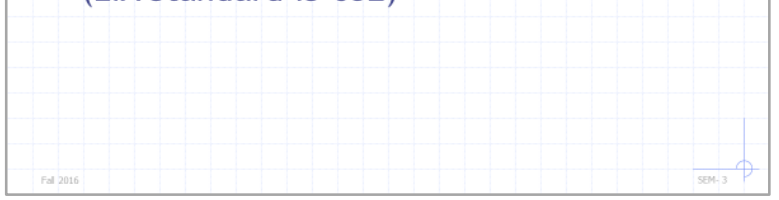

Figure 8 Text Heavy Slide

\section{Key Elements of SEM Definition}

EIA Standard IS-632

An interdisciplinary approach that encompasses the entire technical effort and evolves into and verifies an integrated and life cycle balanced set of system people, products, and process solutions that satisfy customer needs

IEEE P1220， DAU

An interdisciplinary, collaborative approach that derives, evolves, and verifies a life-cycle balanced system solution which satisfies customer expectations and meets public acceptability

Figure 9 Text Heavy Slide with focused highlighting

The key takeaway is that an instructor must ensure they consider the complexity of the information from both a verbal and a visual perspective. This has two aspects. First, if both channels are used, ensure the message is synchronized (i.e., avoid distracting images). Second, and most crucially, do not overwhelm one channel (i.e., reading the slide text out loud).

\subsection{Gestalt Principles}

Gestalt principles relate to the manner in which we automatically group visual objects. This was first described by Wertheimer in the early 1900s [30]. These concepts have been further developed and applied in other fields such as human factors engineering [31].

The Gestalt principle states that humans tend to naturally group visual objects by any obviously similar characteristic such as colour, proximity, motion, size, continuity, etc. This grouping reduces cognitive load by making the information easier to reference or access. An example of gestalt is shown in Figure 10. In this image, most individuals see four groups of circles (one large group on the left and three smaller groups on the right). Though the image has 72 small circles, this is not the immediate impression. Cognitive load on the working memory is reduced as the image is processed as 4 groups versus 72 individual items.

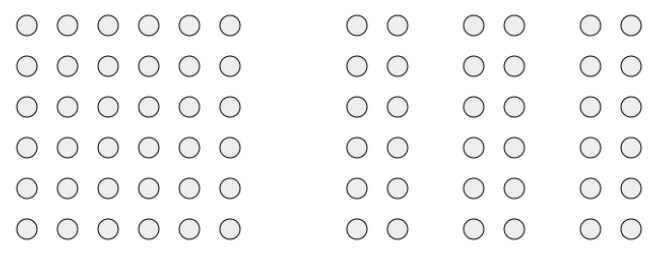

Figure 10 - An example of the Proximity Law of Gestalt

An example of a slide with poor gestalt is shown in Figure 11. In order to parse and understand the information presented, it must all be read. Though the short titles are bolded, the sheer amount of information without any natural grouping creates high cognitive overload.

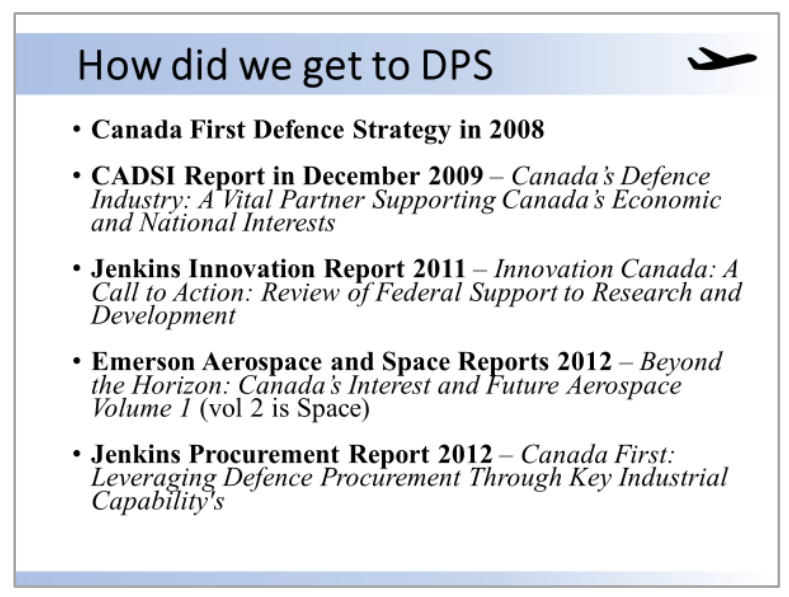

Figure 11 - Slide with traditional list

A slide with the same information, but improved gestalt, is shown in Figure 12. Note that the information is the same, but there are three distinct natural groupings, allowing the information to be parsed independently. First, the year of publication is aligned and bolded on the left. This forms a natural grouping allowing the instructor or student to focus their attention on the timeline. Second, the short titles are on the right and bulleted, forming another natural grouping. Lastly, the sub-bullets are grey and much smaller than the main bullets, as well as separated with white space. This ensures that they are not accidentally grouped with higher-level bullets. However, care should be taken that they are not too small or too faint so that the student can, if required, focus on this last grouping of information. 


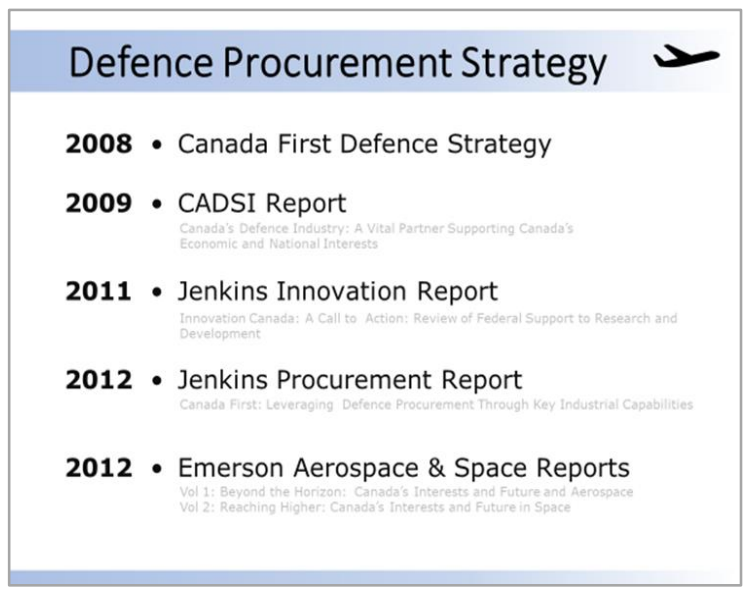

Figure 12 List organized using Gestalt Principles.

The key takeaway is that an instructor must consider how the information on the slide is organized. Using gestalt principles, it is possible to create natural groupings that can reduce the cognitive load on working memory and thus allow the information to be processed and retained more efficiently.

\subsection{Constructivism}

The constructivist theory of learning states that all learning is based on previous learning [32]. All new knowledge is situated within existing knowledge as new linkages are created. Individuals construct their own knowledge based on their own experiences and personal discoveries.

However, research has indicated that unguided discovery can place a high cognitive load on a student [33]. An instructor (or slide) can guide the discovery by encouraging the student to connect new information to the student's existing knowledge. This reduces cognitive load as it is not simply new information that must be learned and memorized, but rather, it is information that already has existing long-term memory components that can be used to retain the new knowledge.

An example of the standard type of definitions slide used in an engineering class is shown in Figure 13.

Though not shown here, the slide was constructed with animation to show each definition sequentially in order to reduce cognitive load. However, this is still simply a list of new information.

An improved slide using constructivist guided discovery is shown in Figure 14. Here, the entire list of definitions is shown all at once, but now the title posits a question about the list, asking the student to think of an example of lean waste that the students may have observed in either their personal or professional life. This guides the students to engage with the new material and connect it to their existing knowledge. The example guiding question shown here is direct, but it can be abstract as "why is this element on the list?" or "what is the most important element on this list?" These reflective questions serve to connect the new information to existing knowledge; thus, helping the student construct new knowledge.

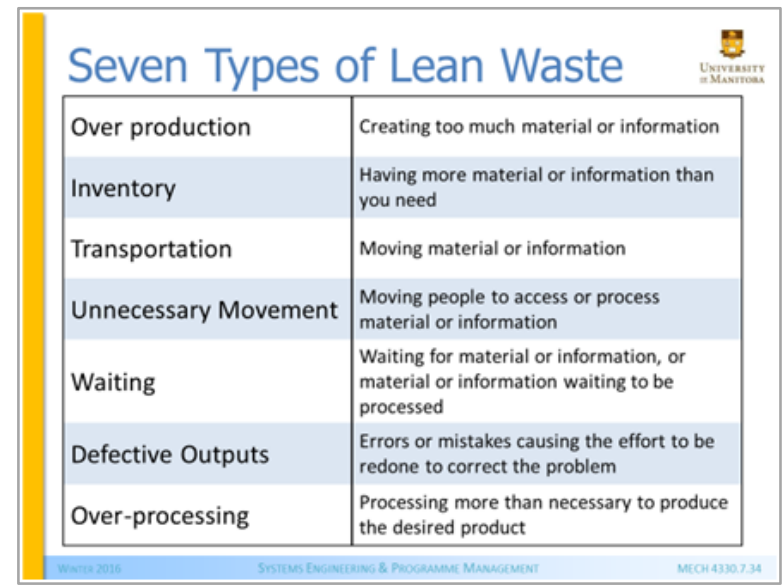

Figure 13 Traditional definitions list slide

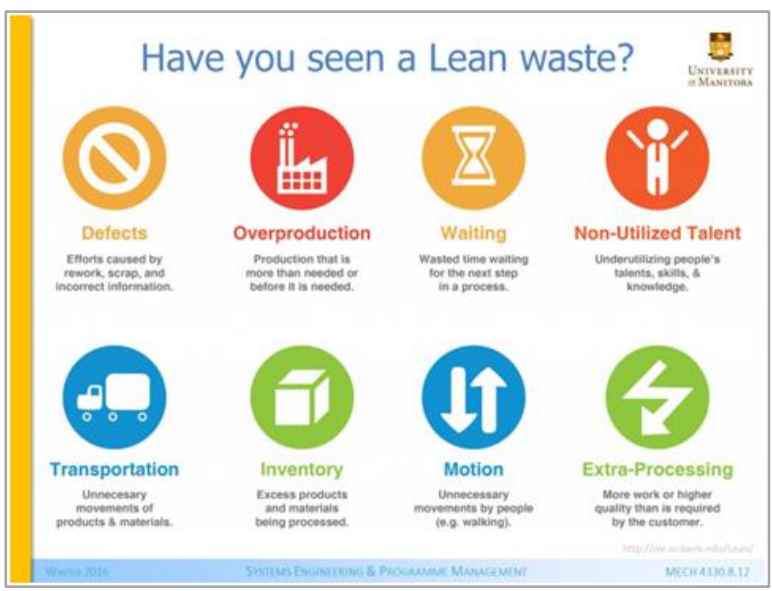

Figure 14 Using guided Constructivism in the title

The key takeaway is that slides should not be used simply to present information. Slides and their titles can be used to guide students to connect new information with their existing information and construct their own knowledge.

\section{SUMMARY}

Though the information presented here focused on the classroom, the underlying principles are applicable to students and professionals wishing to improve their visual rhetoric.

A central factor that leads to low engagement and learning while using slides in an engineering classroom is the cognitive overload endemic in many slide designs. Part of this can be related to the fact that PowerPoint and other presentation tools are designed to display content in peerto-peer situations, vice expert-novice situations. 
However, the classroom is not a boardroom. Students in the engineering classroom are learning new material, and thus under high cognitive load, using their working memory to create new long-term memories (or knowledge). However, as described by Cognitive Load Theory, working memory is a limited resource, capable of handling only a few chunks of information. When overloaded, information is forgotten or lost. Thus, an understanding of the nuances of the processes involved in working memory can be used to reduce the cognitive load of a slide.

First, instructors need to understand the expert-novice divide. What constitutes a single chunk of information for the instructor (such as the steps of a complex process model) may represent many individual pieces of information to the student. Reducing the information on the slide makes it less likely the student will be overwhelmed.

Second, dual-channel theory shows us that working memory is made up of distinct verbal and visual channels. Both have their own independent limits. Care must be taken to ensure not to overwhelm an individual channel (such as speaking while students are reading) to prevent cognitive overload. As well, by ensuring complementary information is presented to both channels, the information can be reinforced.

Third, gestalt principles show us that humans naturally group visual objects based on obvious characteristics such as proximity, colour, shape, etc. Thus, by organizing the layout of information on a slide using spacing and other techniques, we can create groups of information that can be parsed independently. Though the total amount of information on the slide may be large, it can be naturally grouped into smaller chunks, so students do not have to absorb it all at once.

Fourth, the slide can be used to encourage guided discovery. Based on the constructivist learning theory, all knowledge and learning is independently experienced and created based on one's own existing knowledge. However, unguided discovery places a high cognitive load on students. Thus, the slide should be titled with a guiding or reflective question that will help the student to connect this new information with their own existing information in order to construct new understandings.

Applying these theories of cognitive load and working memory to classroom slides can reduce the unintended complexity of the presentation, and thus, enhance student learning and engagement.

\section{Acknowledgements}

We thank the reviewers of this paper, whose suggestions encouraged us to recognize the importance of our analysis outside the classroom environment, add references to relevant expertise, and provided links to the growing field of Visual Rhetoric.

\section{References}

[1] E. Tufte, " PowerPoint Does Rocket Science - and Better Techniques for Technical Reports," 6 September 2005. [Online]. Available: https://www.edwardtufte.com/tufte/powerpoint. [Accessed 25 April 2021].

[2] P. Parker, D. Chao, I. Norman and N. Dunham, Orbiter Assessment of STS-107 ET Bipod, NASA, 2003.

[3] A. Kolmos and E. de Graaff, "Problem-Based and Project-Based Learning in Engineering Education: Merging Models," in Cambridge Handbook of Engineering Education Research, A. Johri and B. Olds, Eds., Cambridge, Cambridge University Press, 2014, pp. 141-160.

[4] C. Atman, O. Eris, J. McDonnell, M. Cardella and J. Borgford-Parnell, "Engineering Design Research: Research, Practice, and Examples that Link the Two," in Cambridge Handbook of Engineering Education Research, A. Johri and B. Olds, Eds., Cambridge, Cambridge University Press, 2014, pp. 201-226.

[5] B. Radhakrishnan, "Advanced Student-Centric Learning Practices in Applied Engineering Programs," in 121st ASEEE Annual Conference \& Exposition, Indianopolis, 2014.

[6] S. Smith, "Pedagogies of Engagement: ClassroomBased Practices," Journal of Engineering Education, vol. 94, no. 1, pp. 87-101, 2005.

[7] N. Nelson and R. Brennan, "Engineering Education: Are Efforts in SOTL Reaching the Engineering Classroom," in Proceedings of the 14th International CDIO Conference, Kanazawa, Japan, 2018.

[8] N. Nelson and R. Brennan, "A Comparison of the Teaching Practices of Novice Educators in Engineering and Other Post-secondary Disciplines," in Proceedings 2020 Canadian Engineering Education Association (CEEA-ACEG20) Conference, Concordia and McGill Universities, 2020.

[9] N. Duarte, Slide:ology: the art and science of creating great presentations, O'Reilly Media, 2008.

[10] R. Altman, Why Most PowerPoint Presentations Suck...and how you can make them better, Harvest Books, 2007.

[11] S. M. Kosslyn, R. A. Kievut, A. G. Russell and J. M. Shephard, "PowerPoint presentation flaws and failures: a psychological analysis," Frontiers in Psychology, vol. 3, no. 230, pp. 1-22, 2012.

[12] B. Hertz, C. van Woerkum and P. Kerkhof, "Why Do Scholars Use PowerPoint the Way They Do?," 
Business and Professional Communication Quarterly, vol. 78, no. 3, pp. 273-291, 2015.

[13] "Better Presenting," [Online]. Available: https://www.betterpresenting.com/.

[14] "ProComm IEEE Conference," [Online]. Available: https://procomm.ieee.org/conference/.

[15] D. Paradi, "Think Outside the Slide," [Online]. Available: https://www.thinkoutsidetheslide.com/freeresources/.

[16] "Visual Rhetoric IEEE," [Online]. Available: https://procomm.iee.org/visuals/.

[17] "Presentation Guild," [Online]. Available: https://presentationguild.org/.

[18] "Bright Carbon," [Online]. Available: https://www.brightcarbon.com/.

[19] S. Ambrose, M. Lovett, M. Bridges, M. DiPietro and M. Norman, How Learning Works: Seven ResearchBased Principles for Smart Teaching, San Francisco, CA: Jossey-Bass, 2010.

[20] P. Kirschner, "Cognitive load theory: implications of cognitive," Learning and Instruction, vol. 12, no. 1, pp. 1-10, 2002.

[21] J. Plass, R. Moreno and R. Brünken, Cognitive Load Theory, Cambridge: Cambridge University Press, 2010.

[22] R. Mayer, Multimedia Learning, 2nd ed., Cambridge: Cambridge University Press, 2009.

[23] C. Wickens, "Information Processing," in Handbook of Human Factors and Ergonomics, G. Salvendy, Ed., Hobokon, New Jersey: John Wiley \& Sons, Inc, 2006, pp. 111-149.

[24] P. Brown, H. Roediger and M. McDaniel, Make it Stick: The Science of Succesful Learning, Cambridge: Harvard University Press, 2014.
[25] G. Miller, "The magical number seven, plus or minus two: Some limits on our Capacity for Processing Information," Psychology Review, vol. 63, no. 1, pp. 81-97, 1956.

[26] National Research Council, How People Learn: Brain, Mind, Experience, and School: Expanded Edition, Washington, D.C.: The National Acadamies Press, 2000.

[27] W. Chase and H. Simon, "Perception and Chess," Cognitive Psychology, no. 1, pp. 33-81, 1973.

[28] A. Baddeley, Exploring Working Memory: Selected Works of Alan Baddeley, Abingdon, Oxford: Routledge, 2018.

[29] S. McLeod, "Working Memory," Simply Psychology, 2012.

[30] R. Spielman, K. Dumper, W. Jenkins, A. Lacombe, M. Lovett and M. Perlmutter, Psychology, OpenStax, 2014.

[31] R. Proctor and J. Proctor, "Sensation and Perception," in Handbook of Human Factors and Ergonomics, 3rd ed., G. Salvendy, Ed., Hoboken, New Jersey: John Wiley \& Sons, Inc., 2006, pp. 5388.

[32] R. Mayer, R. Moreno, M. Boire and S. Vagge, "Maximizing Constructivist Learning From Multimedia Communications by Minimizing Cognitive Load," Journal of Educational Psychology, vol. 91, no. 4, pp. 683-643, 1999.

[33] P. Moreno and P. Babette, "Cognitive Load Theory: Historical Development and Relation to Other Theories," in Cognitive Load Theory, Cambridge University Press, 2010, p. 9-28. 